\title{
The i148m Pnpla3 polymorphism influences serum adiponectin in patients with fatty liver and healthy controls
}

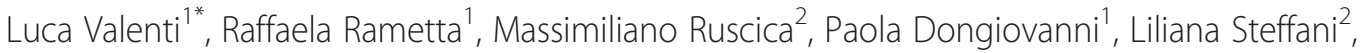
Benedetta Maria Motta ${ }^{1}$, Elena Canavesi ${ }^{1}$, Anna Ludovica Fracanzani' ${ }^{1}$ Enrico Mozzi ${ }^{3}$, Giancarlo Roviaro ${ }^{3}$, Paolo Magni ${ }^{2}$ and Silvia Fargion ${ }^{1}$

\begin{abstract}
Background: Reduced adiponectin is implicated in the pathogenesis of nonalcoholic fatty liver disease (NAFLD) and steatohepatitis (NASH), and the I148M Patatin-like phospholipase domain-containing 3 (PNPLA3) polymorphism predisposes to NAFLD and liver damage progression in NASH and chronic hepatitis C (CHC) by still undefined mechanisms, possibly involving regulation of adipose tissue function. Aim of this study was to evaluate whether the I148M PNPLA3 polymorphism influences serum adiponectin in liver diseases and healthy controls.

Methods: To this end, we considered 144 consecutive Italian patients with NAFLD, 261 with CHC, 35 severely obese subjects, and 257 healthy controls with very low probability of steatosis, all with complete clinical and genetic characterization, including adiponectin (ADIPOQ) genotype. PNPLA3 rs738409 (I148M) and ADIPOQ genotypes were evaluated by Taqman assays, serum adiponectin by ELISA. Adiponectin mRNA levels were evaluated by quantitative real-time PCR in the visceral adipose tissue (VAT) of 35 obese subjects undergoing bariatric surgery.
\end{abstract}

Results: Adiponectin levels were independently associated with the risk of NAFLD and with the histological severity of the disease. Adiponectin levels decreased with the number of $148 \mathrm{M}$ PNPLA3 alleles at risk of NASH both in patients with NAFLD $(p=0.03)$, and in healthy subjects $(p=0.04)$. At multivariate analysis, PNPLA3 $148 \mathrm{M}$ alleles were associated with low adiponectin levels $(<6 \mathrm{mg} / \mathrm{ml}$, median value) independently of NAFLD diagnosis, age, gender, BMI, and ADIPOQ genotype (OR 1.67, 95\% c.i. 1.07-2.1 for each $148 \mathrm{M}$ allele). The p.148 M PNPLA3 variant was associated with decreased adiponectin mRNA levels in the VAT of obese patients $(p<0.05)$ even in the absence of NASH. In contrast, in $\mathrm{CHC}$, characterized by adiponectin resistance, low adiponectin was associated with male gender and steatosis, but not with PNPLA3 and ADIPOQ genotypes and viral features.

Conclusions: The I148M PNPLA3 variant is associated with adiponectin levels in patients with NAFLD and in healthy subjects, but in the presence of adiponectin resistance not in CHC patients. The I148M PNPLA3 genotype may represent a genetic determinant of serum adiponectin levels. Modulation of serum adiponectin might be involved in mediating the susceptibility to steatosis, NASH, and hepatocellular carcinoma in carriers of the 148 M PNPLA3 variant without $\mathrm{CHC}$, with potential therapeutic implications.

Keywords: Adiponectin, Adiponutrin, Chronic hepatitis C, Fibrosis, Gender, Genetics, Nonalcoholic fatty liver disease, Nonalcoholic steatohepatitis, Pnpla3, Steatosis

\footnotetext{
* Correspondence: luca.valenti@unimi.it

'Department of Internal Medicine, Università degli Studi Milano, UO

Medicina Interna 1B, Fondazione IRCCS Ca' Granda Ospedale Maggiore

Policlinico, Milan, Italy

Full list of author information is available at the end of the article
} 


\section{Background}

Paralleling the epidemics of obesity and the metabolic syndrome (MetS), nonalcoholic fatty liver disease (NAFLD) has become the leading cause liver disease in Western countries, affecting $16-34 \%$ of the general population, and a higher proportion of overweight subjects [1]. When complicated by steatohepatitis (NASH), liver damage can progress to cirrhosis and hepatocellular carcinoma [2]. NAFLD is defined by an excess of liver triglycerides in the absence of excessive alcohol intake or exposure to toxics, and is metabolically characterized by insulin resistance (IR), which is more severe in the presence of NASH [3-6]. Increased lipolysis due to adipose tissue IR is key to NAFLD pathogenesis [5,7], and is associated with altered release of adipokines, and in particular adiponectin, a molecule with insulin-sensitizing, anti-inflammatory, and anti-fibrotic effects [8], whose decreased levels have been shown to correlate with hepatic fat accumulation [9-11]. Adipose tissue IR is increased, and adiponectin levels decreased, in patients with severe NASH compared to healthy controls independently of body mass, and correlate with histological improvement after treatment [12]. Overall evidence suggests also the existence of a correlation between adiponectin levels and progressive hepatocellular damage [13]. Defective adiponectin activity has also been demonstrated in chronic hepatitis $\mathrm{C}(\mathrm{CHC})$, but in this case the mechanism seems related to adiponectin resistance, leading to hyper-adiponectinemia, especially in patients with severe fibrosis [14]. However, decreased adiponectin has been associated with steatosis also in CHC [15].

The I148M polymorphism of Patatin-like phospholipase domain-containing 3 (PNPLA3), influences hepatic triglycerides accumulation and the susceptibility to fibrotic NASH in adults and children [16-19], steatosis susceptibility and liver damage progression in $\mathrm{CHC}$ [1922], and progression to hepatocellular carcinoma [21]. Although the I148M variant directly interferes with hepatic lipid metabolism [23-25], it has also been reported to influence adipocytes size and leptin transcription in obese children with NAFLD [26], and in mice deletion of Pnpla3 influenced gene expression in adipose tissue [25], thus suggesting that modulation of adipose tissue function might be involved in the pathogenesis of liver disease associated with the I148M polymorphism. However, no data are available on the effect of I148M PNPLA3 variant on adiponectin levels.

The aim of this study was therefore to assess whether the I148M PNPLA3 variant influences adiponectin in patients with liver diseases characterized by altered adiponectin activity and whose disease progression is influenced by this genetic variant and steatosis, i.e. $\mathrm{NASH}$ and $\mathrm{CHC}$, and in healthy controls with a very low probability of steatosis. To increase the power of the study, the analysis was controlled for adiponectin $($ AdipoQ) genotype, which is the major inherited determinant of adiponectin levels $[27,28]$ and was reported to predispose to steatosis in non-obese non-diabetic subjects [29].

\section{Methods}

\section{Patients}

We considered 144 consecutive unrelated patients of Italian ancestry followed at the Metabolic Liver Diseases outpatient service, Fondazione IRCCS Ca' Granda Ospedale Maggiore Policlinico, with a new diagnosis of NAFLD (without cirrhosis) between January 2008 and January 2010, whose serum (stored at $-80^{\circ} \mathrm{C}$ ) and DNA samples were available. One hundred fifteen patients underwent liver biopsy because of persistently abnormal liver enzymes/serum ferritin or a long lasting history of steatosis associated with severe metabolic abnormalities. Other causes of liver disease were excluded, including increased alcohol intake $(>30 / 20 \mathrm{~g} /$ day for $\mathrm{M} / \mathrm{F}$ ), and carboxydesialylated transferrin determination, viral and autoimmune hepatitis, hereditary hemochromatosis, and alpha1-antitrypsin deficiency.

We considered 261 Italian patients with $\mathrm{CHC}$, all with biopsy, followed at the Metabolic Liver Diseases outpatient service, who were included in a previous study [21], and for whom a serum sample collected at the time of liver biopsy and stored at $-80^{\circ} \mathrm{C}$ was still available.

The control group included 257 blood donors from Northern Italy who were selected because of availability of serum samples stored at $-80^{\circ} \mathrm{C}$, lack of clinical and biochemical evidence of liver and metabolic disease, and no alcohol abuse $(<30 / 20 \mathrm{~g} /$ day in males/females). We excluded subjects with ALT $>35 / 30 \mathrm{IU} / \mathrm{ml}$ in males/ females, GGT $>35 \mathrm{IU} / \mathrm{ml}$, BMI $>28$, abdominal circumference $>100 \mathrm{~cm}$, glucose levels $\geq 100 \mathrm{mg} / \mathrm{dl}$, triglycerides $\geq 150 \mathrm{mg} / \mathrm{dl}, \mathrm{HDL} \leq 45 / 55 \mathrm{in} \mathrm{M} / \mathrm{F}$ or a fatty liver index $>35$, a value with high specificity to rule out NAFLD in the general population [30]. The study protocol was approved by the Institutional Review Board of the Fondazione IRCCS $\mathrm{Ca}^{\prime}$ Granda IRCCS. Informed written consent was obtained from each patient and control subject, and the study conforms to the ethical guidelines of the 1975 declaration of Helsinki. Demographic and clinical features are shown in Table 1.

\section{Histological assessment}

Tissue sections were stained with hematoxylin and eosin, impregnated with silver for reticulin framework, and stained with trichrome for collagen. One expert pathologist unaware of clinical and genetic data reviewed 
Table 1 Demographic, clinical, histological, metabolic features, and PNPLA3 I148M genotype of NAFLD and CHC patients, and healthy controls with very low probability of steatosis

\begin{tabular}{|c|c|c|c|}
\hline & NAFLD patients $(n=144)$ & CHC patients $(n=261)$ & Healthy controls $(n=257)$ \\
\hline $\operatorname{Sex}(F)$ & $32(22 \%)$ & $110^{\wedge}(42 \%)$ & $55(21 \%)$ \\
\hline Age (years) & $49.5 \pm 12$ & $58.1 \pm 14 \wedge$ & $48 \pm 12$ \\
\hline BMI $\left(\mathrm{Kg} / \mathrm{m}^{2}\right)$ & $26.8 \pm 3.3^{\wedge}$ & $25.4 \pm 3.9$ & $25.0 \pm 2.8$ \\
\hline Ferritin (ng/ml) & $470 \pm 420 \wedge$ & $248 \pm 372^{\wedge}$ & $52 \pm 47$ \\
\hline Total cholesterol (mg/dl) & $206 \pm 40$ & $178 \pm 38 \wedge$ & $193 \pm 33$ \\
\hline HDL cholesterol (mg/dl) & $47 \pm 13 \wedge$ & $50 \pm 17 \wedge$ & $57 \pm 13$ \\
\hline Triglycerides (mg/dl) & $133 \pm 64 \wedge$ & $105 \pm 50 \wedge$ & $88 \pm 46$ \\
\hline Glucose (mg/dl) & $98 \pm 27 \wedge$ & $95 \pm 23 \wedge$ & $67 \pm 39$ \\
\hline Diabetes & $17(12 \%)^{\wedge}$ & $47(18 \%)^{\wedge}$ & 0 \\
\hline ALT (IU/ml) & $60 \pm 46 \wedge$ & $70 \pm 59 \wedge$ & $22 \pm 9$ \\
\hline GGT (IU/ml) & $87 \pm 122 \wedge$ & $61 \pm 69 \wedge$ & $21 \pm 13$ \\
\hline Steatosis & $144(100)^{\wedge}$ & $179(69) \wedge$ & 0 \\
\hline Steatosis 2-3 & $41^{*}(36) \wedge$ & $23(9) \wedge$ & 0 \\
\hline NASH & $52^{*}(45)$ & NA & NA \\
\hline Fibrosis & $60^{*}(52)$ & $258(99)$ & NA \\
\hline Cirrhosis & 0 & $80(31)^{\wedge}$ & 0 \\
\hline FFAs $(\mathrm{mmol} / \mathrm{l})^{\circ}$ & $0.22 \pm 0.01 \wedge$ & NA & $0.16 \pm 0.01$ \\
\hline Insulin $(I \mathrm{U} / \mathrm{ml})^{\circ}$ & $14.3\{10.8-20\} \wedge$ & NA & $11.7\{9.2-14.5\}^{\wedge}$ \\
\hline $\mathrm{HOMA}-\mathrm{IR}^{\circ}$ & $3.2\{2.5-4.8\} \wedge$ & NA & $2.5\{1.9-3.2\}$ \\
\hline Adipo-I $\mathrm{R}^{\circ}$ & $14.9 \pm 14.5^{\wedge}$ & NA & $6.1 \pm 2.7$ \\
\hline Adiponectin $(\mu \mathrm{g} / \mathrm{ml})$ & $4.9\{3.0-7.8\} \wedge$ & $9.4\{5.7-13.3\} \wedge$ & $6.6\{4.7-9.3\}$ \\
\hline \multicolumn{4}{|l|}{$A D I P O Q$} \\
\hline rs2241766TT and rs1501299T+ & $83(57)$ & $143(55)$ & $142(55)$ \\
\hline rs2241766G + or rs1501299GG & $61(43)$ & $118(45)$ & $115(45)$ \\
\hline \multicolumn{4}{|l|}{ PNPLA3 rs738409 } \\
\hline CC $(148 \mathrm{I} / \mathrm{l})$ & $55(38)$ & $133(51)$ & $146(57)$ \\
\hline CG (148 I/M) & $68(47)$ & $103(39)$ & $95(37)$ \\
\hline GG (148 M/M) & $21(15)$ & $25(10)$ & $16(6)$ \\
\hline
\end{tabular}

BMI body mass index, HOMA-IR homeostasis model assessment insulin resistance index, NASH nonalcoholic steatohepatitis, FFAs free fatty acids, Adipo-IR adipose tissue insulin resistance index, NA not addressed, ():\% values, ${ }^{*} \mathrm{n}=115$ patients with liver biopsy, adiponectin (ADIPOQ) genotype was classified according to [29], available in all patients and 68 healthy controls, $\wedge p<0.05$ vs. controls.

all biopsies for fibrosis stage. The severity of steatosis, features of NASH and fibrosis was assessed according to Kleiner et al. [31]. NASH was considered to be present when steatosis, ballooning and lobular inflammation were present. In $\mathrm{CHC}$ patients, liver histology was assessed according to Ishak [32]. Liver steatosis was also scored according to Kleiner [31]. The minimum biopsy size was $1.7 \mathrm{~cm}$ and the number of portal areas 10 .

\section{Adiponectin measurement}

All the evaluations have been performed on an aliquot of plasma collected after overnight fasting collected at the time of liver biopsy (when available) of the abdominal ultrasonography and metabolic evaluation, which allowed the diagnosis of NAFLD, and stored at $-80^{\circ} \mathrm{C}$.
Plasma adiponectin levels (all isoforms) were measured using a commercial enzyme-linked immunosorbent assay kit with a lowest limit of sensitivity of $0.246 \mathrm{ng} / \mathrm{mL}$ (R\&D Sytems, Minneapolis, MN) [33]. Insulin levels were evaluated in all patients and 68 healthy controls by the DRG Insulin ELISA kit (DRG International, Mountainside, NJ). Serum FFAs were also evaluated in all patients and 68 healthy controls by the Free fatty acid quantification kit (Biovision Research products, Mountain View, CA). Briefly, FFAs are converted to their CoA derivatives, which are subsequently oxidized with the concomitant generation of color or fluorescence. C-8 (octanoate) and longer fatty acids generated can then be easily quantified by colorimetric (spectrophotometry at $\lambda=570 \mathrm{~nm})$ methods. The adipose tissue insulin 
resistance (Adipo-IR) index was calculated by multiplying fasting FFAs $\mathrm{x}$ insulin (mmol/l / pmol/l) [34].

\section{Adiponectin mRNA evaluation}

In 35 consecutive patients who underwent gastric banding because of morbid obesity (age $45 \pm 10$ years, 5 males, BMI $41.9 \pm 7 \mathrm{Kg} / \mathrm{m}^{2}, 16$ with $\mathrm{NASH}$ ), protocol wedge biopsies of omental visceral adipose tissue (VAT) were performed as a part of a research protocol for which approval of the Ethical Committee and written informed consent were obtained. All patients underwent also liver biopsy at the time of surgical procedure, and all had liver steatosis. Total RNA was isolated by the Trizol reagent (Lifetech, Carlsbad, CA), digested with DNaseI, and quality evaluated by measuring the 260/280 nm absorbance ratio $(\geq 1.8)$ and by electrophoresis. First-strand cDNA was synthesized using equal amounts $(0.5 \mu \mathrm{g})$ of total RNA, with the SuperScript VILO cDNA synthesis kit (Invitrogen, Carlsbad, CA). Adiponectin mRNA levels were analyzed by qRT-PCR with SYBR Green chemistry (Fast SYBR Green master mix, Applied Biosystems, Foster City, CA). All the reactions were performed in triplicate with the ABI 7500 fast quantitative real time (qRT)-PCR system (Lifetech, Carlsbad, CA). Primers are available upon request. Results were normalized for beta actin and HPRT1, which were chosen as a control because of stable expression among different samples, and reported as arbitrary units (i.e. fold expression relative to normalized adiponectin expression of a control sample used as internal standard for calibration of qRTPCR reactions).

\section{Genetic analysis}

DNA was extracted from peripheral blood by the phenol-chloroform method. The adiponutrin/PNPLA3 rs738409 C > G SNP, encoding I148M, was genotyped by a Taqman assay (assay on demand for rs738409, Applied Biosystems, Foster City, CA) by personnel unaware of patients and controls clinical status. Post-PCR allelic discrimination was carried out measuring allele-specific fluorescence on the Opticon2 detection system (MJ Research, Waltham, MA) [17]. Adiponectin (ADIPOQ ) rs2241766, $+45 \mathrm{G}>\mathrm{T}$ and $\mathrm{r} 150299,+276 \mathrm{G}>\mathrm{T}$ polymorphisms, previously associated with the susceptibility to NAFLD [29], were also genotyped by a Taqman assay (assay on demand, Applied Biosystems, Foster City, CA).

\section{Statistical analysis}

Results are expressed as means \pm standard deviation for normally distributed variables, median (interquartile range\} for non-normally distributed variables (e.g. adiponectin), which were log transformed before analysis. Mean values were compared by Anova or Wilcoxon, when appropriate, and frequencies by Fisher's exact test.
Variables were correlated by the Spearman's rho test. Independent predictors of the presence of NAFLD, $\mathrm{NASH}$, and fibrosis, and of low adiponectin levels were determined by logistic regression analysis. Analyses were carried out with the PASW 18.0 (SPSS - IBM, Chicago, IL) and the JMP 6.0 (SAS, Cary, NJ) statistical analysis software.

\section{Results}

Adiponectin levels are associated with NAFLD

As expected, despite similar sex distribution, patients with NAFLD had higher BMI, prevalence of dyslipidemia, IR, increased liver enzymes NAFLD, serum insulin $(\mathrm{p}<0.0001)$, FFAs $(\mathrm{p}<0.0001)$, HOMA-IR $(\mathrm{p}<0.0001)$, Adipo-IR $(\mathrm{p}<0.0001)$, and lower adiponectin levels $(\mathrm{p}=0.008)$ compared to healthy controls with very low probability of steatosis (Table 1). At multivariate logistic regression analysis conducted in patients and controls with complete metabolic data, FFAs (OR 1.013, 95\% c.i. 1.007-1.018; $\mathrm{p}<0.0001$ ) and adiponectin (OR 0.870, 95\% c.i. 0.794-0.953; $\mathrm{p}=0.003$ ) were associated with NAFLD independently of age, sex, BMI, glucose, and insulin levels (Table 2).

\section{Adiponectin, steatosis, and liver damage in subjects with NAFLD}

Adiponectin levels were correlated with serum FFAs (rho $=-0.141 ; \mathrm{p}=0.043$ ), Adipo-IR (rho $=-0.155 ; \mathrm{p}=$ 0.026), ALT levels (rho $=-0.411 ; \mathrm{p}<0.0001$ ), severity of steatosis $(\mathrm{rho}=0.200 ; \mathrm{p}=0.033)$, necroinflammation (rho $=-0.297 ; \mathrm{p}=0.001)$, NAFLD activity score (rho = $-280 ; \mathrm{p}=0.003$ ), and fibrosis stage (rho $=-0.297$, $\mathrm{p}=0.001$ ), and was inversely correlated with fasting insulin $(r h o=-0.156, p=0.002)$. Independent predictors of steatosis grade 2-3, NASH, and the presence of fibrosis in biopsied patients are shown in Table 3. Adiponectin levels were associated with a reduced risk of moderate/ severe steatosis (OR 0.83, 95\% c.i. 0.72-0.96), NASH (OR

Table 2 Independent demographic, anthropometric, and metabolic predictors of the presence of NAFLD at logistic regression analysis in $\mathbf{2 1 2}$ subjects from Northern Italy with complete metabolic data

\begin{tabular}{lccc}
\hline & OR & $\mathbf{9 5 \%}$ c.i. & p \\
\hline Age (years) & 1.016 & $0.98-1.05$ & 0.342 \\
Sex $(\mathrm{M})$ & 2.211 & $0.84-5.81$ & 0.108 \\
BMI $\left(\mathrm{Kg} / \mathrm{m}^{2}\right)$ & 1.368 & $1.17-1.60$ & $<0.0001$ \\
Glucose $(\mathrm{mg} / \mathrm{dl})$ & 0.999 & $0.97-1.03$ & 0.959 \\
Insulin $(\mathrm{IU} / \mathrm{ml})$ & 1.173 & $1.00-1.38$ & 0.055 \\
FFAs $(\mathrm{mmol} / \mathrm{l})$ & 1.013 & $1.01-1.02$ & $<0.0001$ \\
Adiponectin $(\mu \mathrm{g} / \mathrm{ml})$ & 0.870 & $0.79-0.95$ & 0.003 \\
\hline
\end{tabular}

$O R$ odds ratio, c.i. confidence interval, $B M I$ body mass index, FFAs free fatty acids. 
Table 3 Independent predictors of steatosis grade 2-3, NASH, and of fibrosis at logistic regression analysis in 115 consecutive biopsied patients with NAFLD with available DNA and serum samples at the time of liver biopsy

\begin{tabular}{|c|c|c|c|c|c|c|}
\hline \multirow[t]{2}{*}{ Variables } & \multicolumn{2}{|c|}{ Steatosis grade $2-3$ vs. 1} & \multicolumn{2}{|c|}{ NASH vs. simple steatosis } & \multicolumn{2}{|c|}{ Fibrosis vs. no fibrosis } \\
\hline & OR (95\% c.i.) & $p$ value & OR (95\% c.i.) & $p$ value & OR (95\% c.i.) & $p$ value \\
\hline Age (years) & $1.04(0.99-1.09)$ & 0.094 & $1.01(0.96-1.06)$ & 0.598 & $1.06(1.01-1.10)$ & 0.020 \\
\hline $\operatorname{Sex}(F)$ & $1.31(0.40-4.2)$ & 0.656 & $0.88(0.27-2.89)$ & 0.834 & $0.55(0.18-1.65)$ & 0.282 \\
\hline $\mathrm{BMI}\left(\mathrm{Kg} / \mathrm{m}^{2}\right)$ & $1.22(1.04-1.44)$ & 0.014 & $1.32(1.11-1.56)$ & 0.002 & $1.13(0.99-1.30)$ & 0.079 \\
\hline ALT (IU/ml) & $1.02(1.01-1.03)$ & 0.007 & $1.01(1.00-1.02)$ & 0.028 & $1.01(1.00-1.02)$ & 0.028 \\
\hline Glucose (mg/dl) & $0.99(0.98-1.01)$ & 0.217 & $1.03(1.00-1.05)$ & 0.061 & $1.02(0.99-1.04)$ & 0.214 \\
\hline Insulin (IU/ml) & $1.01(0.97-1.06)$ & 0.618 & $0.99(0.94-1.04)$ & 0.654 & $0.98(0.94-1.03)$ & 0.473 \\
\hline FFAs (mmol/l) & $1.00(0.98-1.01)$ & 0.453 & $1.00(0.99-1.01)$ & 0.671 & $1.00(0.99-1.01)$ & 0.934 \\
\hline Adiponectin $(\mu \mathrm{g} / \mathrm{ml})$ & $0.83(0.72-0.96)$ & 0.012 & $0.86(0.75-0.98)$ & 0.025 & $0.84(0.74-0.95)$ & 0.006 \\
\hline
\end{tabular}

OR odds ratio, c.i. confidence interval, BMI body mass index, FFAs free fatty acids; the presence of NASH and fibrosis were defined according to the NASH clinical research network definition [31].

0.86, 95\% c.i. $0.75-0.98$ ), and of fibrosis (OR 0.84, 95\% c.i. 0.74-0.95) independently of age, sex, BMI, ALT, insulin, glucose levels, and FFAs.

\section{PNPLA3 genotype influences adiponectin levels in} subjects without viral hepatitis

The frequency distribution of the I148M PNPLA3 variant was significantly different between patients and controls $(\mathrm{p}<0.0001$; Table 1$)$, due to an over-representation of the $148 \mathrm{M}$ variant in patients, whereas ADIPOQ genotype was not significantly associated with NAFLD (in both male and females). Clinical features of patients and controls with very low probability of steatosis subdivided according to PNPLA3 I148M are shown in Table 4. PNPLA3 I148M genotype was associated with adiponectin levels both in patients $(\mathrm{p}=0.03)$ and in controls $(\mathrm{p}=0.04)$, whereas it did not influence other metabolic features.

In contrast, $A D I P O Q$ genotype was associated with adiponectin levels in controls $(7.6 \pm 3.8$ in rs2241766TT and $\mathrm{rs} 1501299 \mathrm{~T}+\mathrm{vs} .6 .8 \pm 3.8 \mu \mathrm{g} / \mathrm{ml}$ in $\mathrm{rs} 2241766 \mathrm{G}+$ or rs1501299GG; $\mathrm{p}=0.048$ ), but not in patients with NAFLD (not shown). The difference was more marked in males $(6.9 \pm 3.5$ in $\mathrm{rs} 2241766 \mathrm{TT}$ and $\mathrm{rs} 1501299 \mathrm{~T}+\mathrm{vs}$. $5.8 \pm 3.4 \mu \mathrm{g} / \mathrm{ml}$ in $\mathrm{rs} 2241766 \mathrm{G}+$ or $\mathrm{rs} 1501299 \mathrm{GG}$; $\mathrm{p}=0.021$ ), whereas it was not significant in females (not shown). Adiponectin levels in subjects subdivided according to PNPLA3 genotype after stratification for gender and the presence of NAFLD are shown in Figure $1 \mathrm{~A}$. In this subgroup analysis, the I148M variant was significantly associated with adiponectin in females with NAFLD.

In the whole series of subjects without $\mathrm{CHC}$ (Table 5), low adiponectin levels (lower than $6 \mu \mathrm{g} / \mathrm{ml}$, median value in controls) were associated with the presence of NAFLD, age, male gender, BMI, dyslipidemia, ALT, insulin levels, PNPLA3 I148M alleles ( $\mathrm{p}=0.01)$, and ADIPOQ genotype $(\mathrm{p}=0.009)$. Interestingly, the $148 \mathrm{M} P N P L A 3$ allele was associated with low serum adiponectin in subjects carrying the ADIPOQ rs2241766G + or rs1501299GG "low adiponectin" genotypes (50, 47\% 148I/I; 64, 65\% I/M, $20,80 \%, M / M ; p=0.0018)$, but not in those with the rs2241766TT and rs1501299T + "high adiponectin" genotypes $(47,46 \% 148 \mathrm{I} / \mathrm{I} ; 30,45 \% \mathrm{I} / \mathrm{M}, 6,46 \%, \mathrm{M} / \mathrm{M}$; $\mathrm{p}=0.99$ ). At logistic regression analysis (Table 5), low adiponectin levels were associated with NAFLD diagnosis, younger age, male sex, higher BMI, ADIPOQ genotype, and PNPLA3 $148 \mathrm{M}$ alleles (OR 1.67, 95\% c.i. 1.07-2.64 for each $148 \mathrm{M}$ allele carried). In patients with histological NAFLD, PNPLA3 $148 \mathrm{M}$ alleles were associated with low adiponectin levels independently of age, sex, BMI, ADIPOQ genotype, and the severity (grade 1 to 3 ) of steatosis (OR 2.20, 95\% c.i. 1.09-4.80; $\mathrm{p}=0.027$ ).

Effect of I148M PNPLA3 on adiponectin expression in VAT As expected, in severely obese patients VAT adiponectin mRNA levels tended to be lower in patients with $(\mathrm{n}=16)$ than in those without $(\mathrm{n}=19)$ NASH $(2.9 \pm 2.9$ vs. $5.5 \pm 5.8$ arbitrary units $(\mathrm{AU}) ; \mathrm{p}=0.1)$. In this series adiponectin was not significantly associated with gender (possibly due to the very small number of males included), age, and BMI. Adiponectin mRNA levels according to PNPLA3 genotype and NASH are shown in Figure $1 \mathrm{~B}$. The presence of the $148 \mathrm{M}$ variant was associated with lower adiponectin even in the absence of NASH $(2.2 \pm 2, \mathrm{n}=10$ vs. $9.0 \pm 10, \mathrm{n}=9 ; \mathrm{p}=0.050)$.

\section{Effect of PNPLA3 genotype on adiponectin levels in $\mathrm{CHC}$ patients}

Clinical features of $\mathrm{CHC}$ patients subdivided according to PNPLA3 genotype are presented in Table 6. PNPLA3 genotype was associated with steatosis $(\mathrm{p}=0.02)$, severe steatosis $(\mathrm{p}<0.0001)$, and nearly associated with cirrhosis $(p=0.06)$, but was not significantly associated with metabolic features. 
Table 4 Clinical features of 144 NAFLD patients and 257 healthy controls with very low probability of steatosis from Northern Italy according to the PNPLA3 I148M genotype

\begin{tabular}{|c|c|c|c|c|}
\hline \multirow[b]{2}{*}{ PNPLA3 genotype } & \multicolumn{3}{|c|}{ NAFLD patients $(n=144)$} & \multirow[t]{2}{*}{ p value* } \\
\hline & $C C(n=55)$ & CG $(n=68)$ & $G G(n=21)$ & \\
\hline Age (years) & $49 \pm 13$ & $51 \pm 12$ & $47 \pm 12$ & 0.87 \\
\hline $\operatorname{Sex}(F)$ & $15(27)$ & $12(18)$ & $5(24)$ & 0.58 \\
\hline BMI $\left(\mathrm{Kg} / \mathrm{m}^{2}\right)$ & $26.8 \pm 3.7$ & $27.1 \pm 3.1$ & $26.0 \pm 3.0$ & 0.62 \\
\hline ALT (IU/ml) & $54 \pm 38$ & $58 \pm 49$ & $80 \pm 54$ & 0.06 \\
\hline Diabetes & $3(5.5)$ & $11(16.2)$ & $3(14.3)$ & 0.13 \\
\hline Insulin (IU/ml) & $14.6\{11.7-19.9\}$ & $13.4\{10.2-20.2\}$ & $16.8\{11.5-22.1\}$ & 0.33 \\
\hline Glucose & $94 \pm 21$ & $101 \pm 34$ & $97 \pm 16$ & 0.43 \\
\hline HOMA-IR & $3.1\{2.5-4.5\}$ & $3.3\{2.4-4.5\}$ & $3.3\{2.4-5.5\}$ & 0.57 \\
\hline FFAs (mmol/l) & $0.21 \pm 0.09$ & $0.22 \pm 0.08$ & $0.22 \pm 0.09$ & 0.85 \\
\hline Adipo-IR & $14.2 \pm 15.1$ & $13.9 \pm 13.9$ & $17.9 \pm 15.4$ & 0.78 \\
\hline \multirow[t]{2}{*}{ Adiponectin $(\mu \mathrm{g} / \mathrm{ml})$} & $5.5\{3.0-9.9\}$ & $4.9\{3.0-7.4\}$ & $3.8\{2.7-6.5\}$ & 0.03 \\
\hline & \multicolumn{3}{|c|}{ Controls $(n=257)$} & $p$ value* \\
\hline PNPLA3 genotype & $C C(n=146)$ & $C G(n=95)$ & $\mathrm{GG}(\mathrm{n}=16)$ & \\
\hline Age (years) & $46 \pm 12$ & $51 \pm 12$ & $45 \pm 14$ & 0.51 \\
\hline $\operatorname{Sex}(F)$ & $37(25)$ & $15(16)$ & $3(19)$ & 0.83 \\
\hline BMI $\left(\mathrm{Kg} / \mathrm{m}^{2}\right)$ & $24.8 \pm 2.7$ & $25.2 \pm 2.8$ & $25.2 \pm 4.2$ & 0.71 \\
\hline ALT (IU/ml) & $21 \pm 7$ & $24 \pm 8$ & $22 \pm 6$ & 0.48 \\
\hline Insulin ${ }^{\circ}(\mathrm{IU} / \mathrm{ml})$ & $11.8\{9.5-14.0\}$ & $11.9\{9.2-15.4\}$ & $9.0\{7.6-14.8\}$ & 0.17 \\
\hline Glucose & $89 \pm 6$ & $89 \pm 6$ & $86 \pm 3$ & 0.89 \\
\hline HOMA-IR & $2.5\{1.9-3.2\}$ & $2.6\{2.0-3.4\}$ & $1.8\{1.7-3.0\}$ & 0.10 \\
\hline $\mathrm{FFAs}^{\circ}(\mathrm{mmol} / \mathrm{l})$ & $0.16 \pm 0.07$ & $0.14 \pm 0.06$ & $0.23 \pm 0.02$ & 0.93 \\
\hline Adipo- $\mathbb{R}^{\circ}$ & $6.4 \pm 2.8$ & $5.2 \pm 2.1$ & $8.1 \pm 0.9$ & 0.47 \\
\hline Adiponectin $(\mu \mathrm{g} / \mathrm{ml})$ & $7.0\{4.7-9.9\}$ & $6.2\{4.7-8.8\}$ & $5.6\{4.2-7.4\}$ & 0.04 \\
\hline
\end{tabular}

* $\mathrm{p}$ for trend across PNPLA3 genotypes, ${ }^{\circ}$ available in 68 controls. BMI body mass index, IFG impaired fasting glucose, HOMA-IR homeostasis model assessment insulin resistance index, FFAs free fatty acids, Adipo-IR adipose tissue insulin resistance index, ():\% values, \{\}: interquartile range.

Adiponectin levels were higher in subjects with $\mathrm{CHC}$ (with and without steatosis) than in those without $\mathrm{CHC}$ (NAFLD patients and healthy controls): $9.4\{5.7-13.2\}$ vs. $5.8\{3.9-8.9\} \mu \mathrm{g} / \mathrm{ml} ; \mathrm{p}<0.0001$. At multivariate logistic regression analysis, the association between adiponectin and $\mathrm{CHC}$ was independent of age, gender, $\mathrm{BMI}$, the presence of steatosis, and $A D I P O Q$ genotype (OR 1.10, 95\% c.i. 1.03-1.19; $\mathrm{p}=0.0009)$. Variables associated with low adiponectin levels in $\mathrm{CHC}$ patients are shown in Table 7. Low adiponectin levels were associated with steatosis, age, male gender, dyslipidemia, cirrhosis, and viral genotype 4 (patients carrying genotype 4 were all males), nearly associated with $A D I P O Q$ genotype ( $\mathrm{p}=0.068$ ), but not with PNPLA3 I148M genotype $(\mathrm{p}=\mathrm{ns})$. However, there was an association between the $148 \mathrm{M} / \mathrm{M}$ genotype low adiponectin levels in subjects carrying the "high adiponectin" rs2241766TT and rs1501299T + genotypes $(6,46 \%$ vs. $20,19 \% ; \mathrm{p}=0.026)$. There was no significant association between adiponectin and viral load, other viral genotypes, and the histological activity of the disease (not shown). At logistic regression analysis (Table 7), low adiponectin levels were associated with male sex, younger age, and steatosis, but not with PNPLA3 and ADIPOQ genotypes.

\section{Discussion}

As decreased adiponectin, a molecule which antagonizes hepatic lipid accumulation and has insulin-sensitizing, anti-inflammatory, and anti-fibrotic effects [8] plays a pivotal role in NAFLD pathogenesis [9-11,13], and the I148M PNPLA3 polymorphism involved in the regulation of lipid metabolism predisposes to the progression of liver diseases associated with steatosis by still undefined mechanisms, we evaluated whether PNPLA3 genotype influenced adiponectin levels. Our results support the hypothesis that PNPLA3 genotype is a determinant of serum adiponectin in patients with NAFLD, in particular in females, and in healthy controls, independently of acquired factors, and of $A D I P O Q$ $[27,28]$. 


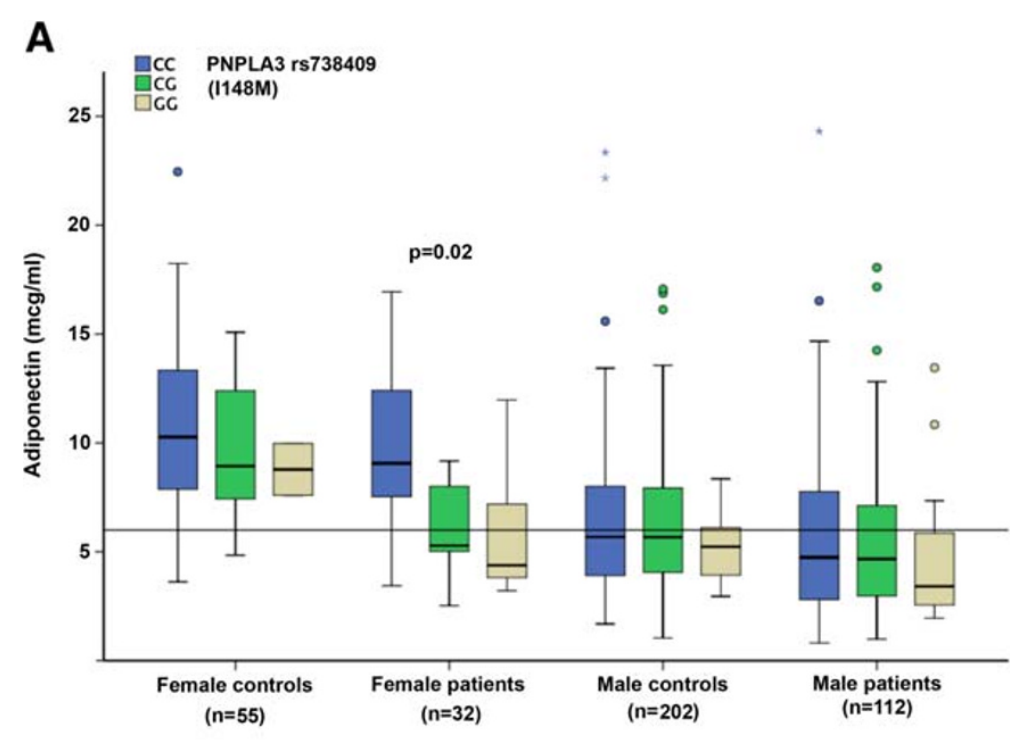

B

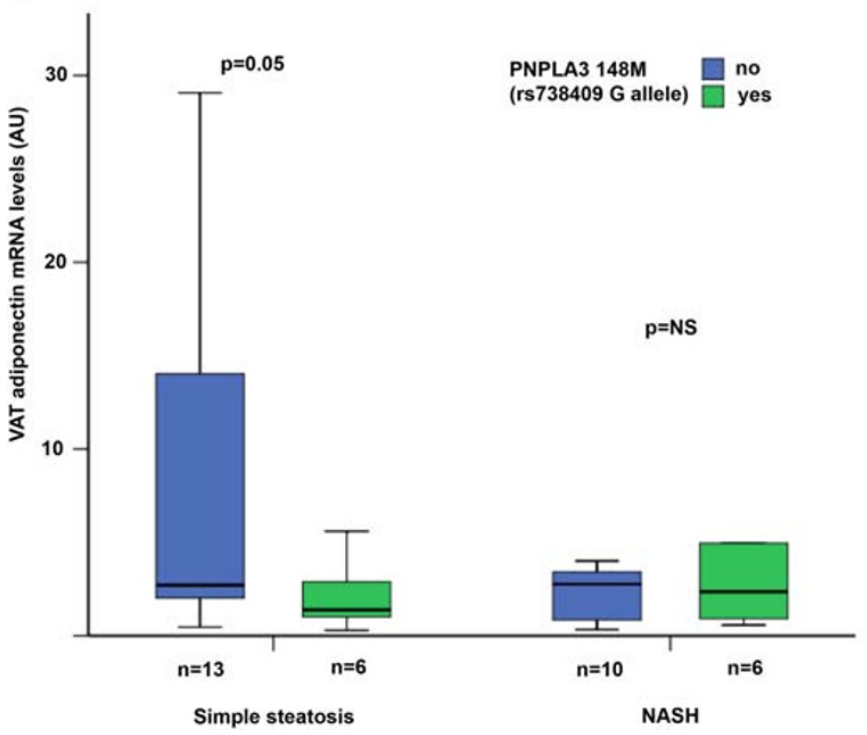

Figure 1 Effect of PNPLA3 genotype on serum adiponectin. A) Adiponectin levels according to I148M PNPLA3 genotype in subjects stratified according to gender and NAFLD diagnosis vs. healthy controls. B) Adiponectin mRNA levels (AU: arbitrary units) in VAT of morbidly obese patients according to the presence of NASH and I148M PNPLA3 genotype.

We preliminarily confirmed that patients with NAFLD displayed lower adiponectin than healthy controls [13]. Although we did not exclude steatosis by imaging in all control subjects, the metabolic and clinical selection criteria used have a high specificity to exclude this condition in the general population [30], and the different distribution of PNPLA3 genotype between patients and healthy subjects with very low probability of steatosis indirectly confirmed the accurate selection of controls $[16,17]$. Moreover, in patients with NAFLD low adiponectin was independently associated with the severity of steatosis, as well as with NASH and fibrosis, in line with the hypothesized role of adiponectin in the progression of liver damage $[9,11,13,35]$.

The I148M PNPLA3 variant is a major risk factor for the development and progression of NAFLD $[16-18,22,36]$, but the mechanism linking the $148 \mathrm{M}$ allele to increased liver fat, inflammation, and fibrogenesis, and the tissue specificity of PNPLA3 physiological activity are still under definition [25,37]. The 148 M PNPLA3 allele was previously associated with adipocytes of smaller size, a marker of metabolic derangement, and increased leptin transcription in a small group of obese children with NAFLD [26], thus suggesting that 
Table 5 Variables associated with and independent predictors of low adiponectin levels (<6 mg/ml) in 144 NAFLD patients and 257 healthy controls with very low probability of steatosis

\begin{tabular}{|c|c|c|c|c|c|}
\hline Adiponectin & Low $(n=217)$ & High $(n=194)$ & $\mathbf{p}$ & OR * $(95 \%$ c.i. $)$ & $\mathbf{p}^{*}$ \\
\hline NAFLD present & $89(46)$ & $52(24)$ & 0.002 & $1.65(1.02-2.70)$ & 0.043 \\
\hline Age (years) & $46 \pm 11$ & $51 \pm 13$ & 0.007 & $0.96(0.94-0.98)$ & $<0.0001$ \\
\hline $\operatorname{Sex}(F)$ & $20(9)$ & $67(34)$ & $<0.0001$ & $0.21(0.11-0.37)$ & $<0.0001$ \\
\hline BMI $\left(\mathrm{Kg} / \mathrm{m}^{2}\right)$ & $26.2 \pm 3.0$ & $25.0 \pm 3.1$ & $<0.0001$ & $1.15(1.07-1.25)$ & 0.0002 \\
\hline $\mathrm{HDL}(\mathrm{mg} / \mathrm{dl})$ & $48 \pm 12$ & $57 \pm 14$ & $<0.0001$ & - & - \\
\hline Triglycerides (mg/dl) & $119 \pm 68$ & $92 \pm 47$ & $<0.0001$ & - & - \\
\hline ALT (IU/ml) & $42 \pm 38$ & $29 \pm 25$ & $<0.0001$ & - & - \\
\hline Insulin (IU/ml) & $17 \pm 14$ & $13 \pm 8$ & 0.003 & - & - \\
\hline FFAs (mmol/l) & $0.21 \pm 0.09$ & $0.19 \pm 0.08$ & 0.05 & - & - \\
\hline \multicolumn{6}{|l|}{$A D I P O Q$} \\
\hline rs2241766TT and rs1501299T+ & $83(38)$ & $100(52)$ & 0.008 & $0.61(0.39-0.95)$ & 0.030 \\
\hline rs2241766G + or rs1501299GG & $134(62)$ & $94(48)$ & & reference & \\
\hline \multicolumn{6}{|l|}{ PNPLA3 rs738409 } \\
\hline CC (148 I/I) & $97(45)$ & $112(58)$ & 0.01 & $1.67^{\circ}(1.07-2.64)$ & 0.024 \\
\hline CG (148 I/M) & $94(43)$ & $71(37)$ & & & \\
\hline GG (148 M/M) & $26(12)$ & $11(6)$ & & & \\
\hline
\end{tabular}

():\% values; * OR of low adiponectin at logistic regression analysis considering as independent variables the presence or not of NAFLD, age, gender, BMI, ADIPOQ and PNPLA3 genotype (additive model; OR per number of variant $148 \mathrm{M}$ alleles).

modulation of adipose tissue endocrine activity may be implicated in the mechanism by which PNPLA3 influences NASH susceptibility. In the present study, we could not detect a significant association between PNPLA3, FFAs, and insulin resistance [36], whereas in line with the experimental hypothesis PNPLA3 genotype influenced serum adiponectin levels. Indeed, we observed a dose dependent relationship between the $148 \mathrm{M}$ variant and adiponectin, which was evident in both in healthy controls and patients with NAFLD, but, due to the very well known gender-specific dimorphism of adiponectin levels which are higher in females [8], it more frequently contributed to hypo-adiponectinemia in females. Interestingly, these data may contribute to explain the significant interaction between PNPLA3 I148M genotype and female gender on NAFLD risk observed in the recent meta-

Table 6 Clinical features of 261 CHC patients from Northern Italy according to the PNPLA3 I148M genotype

\begin{tabular}{|c|c|c|c|c|}
\hline PNPLA3 genotype & $C C n=133(51)$ & CG $n=103(39)$ & GG $n=25(10)$ & $p$ value \\
\hline Age (years) & $57 \pm 14$ & $59 \pm 14$ & $57 \pm 14$ & 0.47 \\
\hline $\operatorname{Sex}(F)$ & $58(44)$ & $46(45)$ & $6(24)$ & 0.16 \\
\hline $\mathrm{BMI}\left(\mathrm{Kg} / \mathrm{m}^{2}\right)$ & $25.2 \pm 3.4$ & $25.3 \pm 3.9$ & $26.6 \pm 6.1$ & 0.25 \\
\hline ALT (IU/ml) & $72 \pm 56$ & $67 \pm 58$ & $73 \pm 78$ & 0.81 \\
\hline Diabetes & $26(20)$ & $17(17)$ & $4(16)$ & 0.80 \\
\hline Insulin (IU/ml) & $21\{14-27\}$ & $20\{17-27\}$ & $17\{12-25\}$ & 0.61 \\
\hline Glucose & $95 \pm 22$ & $96 \pm 26$ & $93 \pm 22$ & 0.85 \\
\hline Total cholesterol (mg/dl) & $176 \pm 36$ & $177 \pm 41$ & $178 \pm 41$ & 0.95 \\
\hline HDL cholesterol (mg/dl) & $50 \pm 15$ & $51 \pm 18$ & $48 \pm 15$ & 0.66 \\
\hline Triglycerides (mg/dl) & $108 \pm 43$ & $104 \pm 61$ & $88 \pm 31^{*}$ & 0.24 \\
\hline HOMA-IR & $4.7\{3.2-5.8\}$ & $4.5\{3.4-6.6\}$ & $3.8\{2.3-6.5\}$ & 0.62 \\
\hline Adiponectin $(\mu \mathrm{g} / \mathrm{ml})$ & $9.3\{5.8-13\}$ & $9.4\{5.7-14\}$ & $9.7\{5.3-13\}$ & 0.93 \\
\hline Steatosis & $85(64)$ & $72(70)$ & $22(88)$ & 0.02 \\
\hline Severe steatosis (> 33\%) & $8(6)$ & $7(7)$ & $8(32)$ & $<0.0001$ \\
\hline Cirrhosis & $34(26)$ & $36(35)$ & $10(40)$ & 0.06 \\
\hline
\end{tabular}

():\% values; \{\}: interquartile range, reported with median value; ${ }^{*} \mathrm{p}<0.05$ vs. other genotypes. 
Table 7 Variables associated with and independent predictors of low adiponectin serum levels (<6 $\mu \mathrm{g} / \mathrm{ml})$ in $261 \mathrm{CHC}$ patients

\begin{tabular}{|c|c|c|c|c|c|}
\hline Adiponectin & Low $(n=72)$ & High $(n=189)$ & $\mathbf{p}$ & OR * $(95 \%$ c.i. $)$ & $p^{*}$ \\
\hline Steatosis present & $59(82)$ & $120(63)$ & 0.004 & $3.85(1.78-8.91)$ & 0.0005 \\
\hline Age (years) & $51 \pm 14$ & $61 \pm 13$ & $<0.0001$ & $0.95(0.92-0.97)$ & $<0.0001$ \\
\hline $\operatorname{Sex}(F)$ & $10(14)$ & $100(53)$ & $<0.0001$ & $0.18(0.08-0.38)$ & $<0.0001$ \\
\hline $\mathrm{HDL}(\mathrm{mg} / \mathrm{dl})$ & $42 \pm 11$ & $53 \pm 17$ & $<0.0001$ & - & - \\
\hline Triglycerides (mg/dl) & $121 \pm 71$ & $98 \pm 38$ & 0.012 & - & - \\
\hline Cirrhosis & $15(21)$ & $65(34)$ & 0.036 & $0.65(0.30-1.40)$ & 0.277 \\
\hline Viral genotype 4 & $11(15)$ & $8(4)$ & 0.0055 & $1.68(0.55-5.70)$ & 0.456 \\
\hline \multicolumn{6}{|l|}{ ADIPOQ } \\
\hline rs2241766TT and rs1501299T+ & $26(36)$ & $92(49)$ & 0.068 & $0.74(0.39-1.40)$ & 0.355 \\
\hline rs2241766G + or rs1501299GG & $46(64)$ & $97(51)$ & & reference & \\
\hline \multicolumn{6}{|l|}{ PNPLA3 rs738409 } \\
\hline CC $(148 \mid / l)$ & $34(47)$ & $99(52)$ & 0.73 & $1.15(0.71-2.80)$ & 0.600 \\
\hline CG (148 I/M) & $30(42)$ & $73(39)$ & & & \\
\hline GG (148 M/M) & $8(11)$ & $17(9)$ & & & \\
\hline
\end{tabular}

():\% values; * OR of low adiponectin values at logistic regression analysis considering as independent variables the presence or not of NAFLD, age, gender, BMI ALT, and ADIPOQ and PNPLA3 genotype (additive model; OR per number of $148 \mathrm{M}$ alleles).

analysis by Sookoian et al. [36]. The observation that even in the absence of NASH severely obese patients carrying the $148 \mathrm{M}$ variant had decreased VAT adiponectin mRNA expression is also in line with these findings and suggests that the reduced serum adiponectin associated with this genetic polymorphism is determined by impaired transcription of the gene in the adipose tissue. However, given the relatively limited number of subjects analyzed (in particular of obese subjects), the relationship between PNPLA3 genotype and adiponectin, and the lack of association with IR should be confirmed in further studies. Indeed, recent studies have reported an association of the PNPLA3 I148M variant with IR and lower levels of triglycerides in severely obese subjects [38,39], suggesting that in the presence of environmental triggering factors PNPLA3 is indeed a modulator of hepatic IR and lipoprotein secretion.

Furthermore, although the association between PNPLA3 genotype and adiponectin was independent of steatosis severity in patients with NAFLD, our results does not exclude that PNPLA3 may modulate adipose tissue indirectly by regulating the secretion of hepatokines such as fetuin [40], and that it may also modulate other proinflammatory molecules such as resistin and ICAM-1 $[26,41]$.

The genetic determinants of serum adiponectin levels, a strongly heritable trait, have been recently evaluated in genome-wide association studies [27,28]. Although no association with PNPLA3 has emerged so far, only a small fraction $(<10 \%)$ of adiponectin heritability has been determined, and none of the studies considered patients with NAFLD. The strongest genetic determinant of adiponectin levels is ADIPOQ [27,28], and $A D I P O Q$ SNPs have been associated with steatosis and progressive NASH in lean patients without diabetes and dyslipidemia [29]. In this study, we characterized $A D I P O Q$ genotype, which allowed to adjust the results for a major confounder and to unveil a possible interaction between ADIPOQ and PNPLA3 in determining adiponectin levels. The lack of association between $A D I P O Q$ and NAFLD risk may be explained by the different inclusion criteria in our study compared to the previous [29].

On the other hand, despite in line with previous findings PNPLA3 genotype influenced steatosis in $\mathrm{CHC}$ and was possibly associated with lower triglycerides, in these patients PNPLA3 and ADIPOQ were not significantly associated with adiponectin, possibly due to development of adiponectin resistance associated with chronic $\mathrm{HCV}$ infection, in particular in patients with more severe disease [14]. Adiponectin resistance could modify the interaction between genotype and environmental factors, decreasing the effect size of genetic variants, so that the power of the present study was not sufficient to detect significant differences in adiponectin levels. This conclusion is supported by our data indicating that $\mathrm{CHC}$ is independently associated with higher adiponectin, previously ascribed to decreased adiponectin receptor-1 mediated clearance [14], in particular in the presence of advanced fibrosis [14]. In contrast, although cirrhotic patients were not included in the NAFLD group, adiponectin levels decreased with the severity of liver damage in patients with steatosis, in line with the results of a recent meta-analysis [13]. 


\section{Conclusions}

In conclusion, our data suggest that the I148M PNPLA3 genotype may represent a genetic determinant of serum adiponectin levels. Modulation of serum adiponectin might be involved in mediating the susceptibility to steatosis, NASH, and hepatocellular carcinoma in carriers of the $148 \mathrm{M}$ PNPLA3 variant without $\mathrm{CHC}$, with potential therapeutic implications, but additional studies are required to confirm this hypothesis.

\begin{abstract}
Abbreviations
Adipo-IR: Adipose tissue insulin resistance index; ALT: Alanine transaminase; AST: Aspartate transaminase; BMI: Body mass index; c.i.: Confidence interval; FFAs: Free fatty acids; GGT: Gamma-glutamyl transferase; HOMAIR: Homeostasis model assessment insulin resistance index; IR: Insulin resistance; MetS: Metabolic syndrome; NAFLD: Nonalcoholic fatty liver disease; NAS: Nonalcoholic fatty liver disease activity score; NASH: Nonalcoholic steatohepatitis; PNPLA3: Patatin like phospholipase domain containing -3; SNP: Single nucleotide polymorphism; VAT: Visceral adipose tissue.
\end{abstract}

\section{Competing interests}

The authors declare that they have no competing interest to disclose.

\section{Authors' contribution}

LV designed the study, analyzed and interpreted the data and wrote the manuscript draft. RR, BMM, and PD performed genetic and gene expression analyses and contributed to data analyses, MR, LS, and PM measured serum adiponectin and contributed to data analysis, EC contributed to data analysis and to manuscript drafting, EM and GCR collected and processed tissue samples and contributed to data analysis, AF collected clinical data, SF contributed to data interpretation and supervised the study. All Authors read and approved the final manuscript version.

\section{Authors' information}

Luca Valenti is assistant professor of Internal Medicine at the Metabolic Liver Diseases Center, directed by prof. S. Fargion, of the Università degli Studi di Milano, Fondazione Ca' Granda IRCCS Ospedale Maggiore Policlinico. He coordinates a research team contributing to this paper, and his main research interests include metabolic liver diseases, and in particular nonalcoholic fatty liver disease and hereditary hemochromatosis, iron metabolism, and the role of genetics in hepatology. The research group has recently contributed to unravel the role of PNPLA3 in the progression of liver damage in liver diseases associated with steatosis. He has established collaborations with prof. Giancarlo Roviaro, Department of Surgery Università degli Studi di Milano, for the study of genetic factors influencing hepatological complications in severily obese patients undergoing bariatric surgery, and with Paolo Magni and Massimiliano Ruscica, Department of Endocrinology, Pathophysiology and Applied Biology, Università degli Studi Milano, for the study of endocrinological and metabolic alterations associated with nonalcoholic fatty liver disease.

\section{Financial support}

The work was supported by the following grants: FIRST Università degli Studi di Milano 2007, 2008 (LV, SF: www.unimi.it); Ricerca corrente Ospedale Maggiore Policlinico 2006 and 2008 (LV, SF; www.policlinico.mi.it); and Centro per lo Studio delle Malattie del Fegato e del Metabolismo. The funders had no role in study design, data collection and analysis, decision to publish, or preparation of the manuscript.

\section{Acknowledgements}

We thank Paolo Maggioni, Cristina Bertelli, Erika Fatta, and Daniela Bignamini for clinical assistance.

\section{Author details}

${ }^{1}$ Department of Internal Medicine, Università degli Studi Milano, UO Medicina Interna 1B, Fondazione IRCCS Ca' Granda Ospedale Maggiore
Policlinico, Milan, Italy. ${ }^{2}$ Department of Endocrinology, Pathophysiology and Applied Biology, Università degli Studi Milano, Milan, Italy. ${ }^{3}$ Department of Surgery, Università degli Studi Milano, Ospedale Maggiore "Ca' Granda" Fondazione Policlinico IRCCS, Milan, Italy.

Received: 5 March 2012 Accepted: 7 August 2012 Published: 16 August 2012

\section{References}

1. Bellentani S, Saccoccio G, Masutti F, Croce LS, Brandi G, Sasso F, Cristanini G, Tiribelli C: Prevalence of and risk factors for hepatic steatosis in Northern Italy. Ann Intern Med 2000, 132(2):112-117.

2. Bugianesi E, Leone N, Vanni E, Marchesini G, Brunello F, Carucci P, Musso A De Paolis P, Capussotti L, Salizzoni M, et al: Expanding the natural history of nonalcoholic steatohepatitis: from cryptogenic cirrhosis to hepatocellular carcinoma. Gastroenterology 2002, 123(1):134-140.

3. Marchesini G, Brizi M, Bianchi G, Tomassetti S, Bugianesi E, Lenzi M, McCullough AJ, Natale S, Forlani G, Melchionda N: Nonalcoholic fatty liver disease: a feature of the metabolic syndrome. Diabetes 2001, 50(8):1844-1850.

4. Valenti L, Rametta R, Dongiovanni P, Maggioni M, Fracanzani AL, Zappa M, Lattuada E, Roviaro G, Fargion S: Increased expression and activity of the transcription factor FOXO1 in nonalcoholic steatohepatitis. Diabetes 2008, 57(5):1355-1362

5. Bugianesi E, Gastaldelli A, Vanni E, Gambino R, Cassader M, Baldi S, Ponti V, Pagano G, Ferrannini E, Rizzetto M: Insulin resistance in non-diabetic patients with non-alcoholic fatty liver disease: sites and mechanisms. Diabetologia 2005, 48(4):634-642.

6. Kotronen A, Juurinen L, Tiikkainen M, Vehkavaara S, Yki-Jarvinen $\mathrm{H}$ : Increased liver fat, impaired insulin clearance, and hepatic and adipose tissue insulin resistance in type 2 diabetes. Gastroenterology 2008, 135(1):122-130.

7. Donnelly KL, Smith Cl, Schwarzenberg SJ, Jessurun J, Boldt MD, Parks EJ: Sources of fatty acids stored in liver and secreted via lipoproteins in patients with nonalcoholic fatty liver disease. J Clin Invest 2005, 115 (5):1343-1351.

8. Kadowaki T, Yamauchi T: Adiponectin and adiponectin receptors. Endocr $\operatorname{Rev} 2005,26(3): 439-451$.

9. Bugianesi E, Pagotto U, Manini R, Vanni E, Gastaldelli A, de lasio R, Gentilcore E, Natale S, Cassader M, Rizzetto M, et al: Plasma adiponectin in nonalcoholic fatty liver is related to hepatic insulin resistance and hepatic fat content, not to liver disease severity. J Clin Endocrinol Metab 2005, 90(6):3498-3504.

10. Musso G, Gambino R, Biroli G, Carello M, Faga E, Pacini G, De Michieli F, Cassader M, Durazzo M, Rizzetto M, et al: Hypoadiponectinemia predicts the severity of hepatic fibrosis and pancreatic Beta-cell dysfunction in nondiabetic nonobese patients with nonalcoholic steatohepatitis. Am J Gastroenterol 2005, 100(11):2438-2446.

11. Bianchi G, Bugianesi E, Frystyk J, Tarnow L, Flyvbjerg A, Marchesini G: Adiponectin isoforms, insulin resistance and liver histology in nonalcoholic fatty liver disease. Dig Liver Dis 2010, 43(1):73-77.

12. Gastaldelli A, Harrison SA, Belfort-Aguilar R, Hardies LJ, Balas B, Schenker S, Cusi $\mathrm{K}$ : Importance of changes in adipose tissue insulin resistance to histological response during thiazolidinedione treatment of patients with nonalcoholic steatohepatitis. Hepatology 2009, 50(4):1087-1093.

13. Polyzos SA, Toulis KA, Goulis DG, Zavos C, Kountouras J: Serum total adiponectin in nonalcoholic fatty liver disease: a systematic review and meta-analysis. Metabolism 2010, 60(5):313-326.

14. Corbetta S, Redaelli A, Pozzi M, Bovo G, Ratti L, Redaelli E, Pellegrini C, Beck-Peccoz P, Spada A: Fibrosis is associated with adiponectin resistance in chronic hepatitis C virus infection. Eur J Clin Invest 2011, 41(8):898-905.

15. Petit JM, Minello A, Jooste V, Bour JB, Galland F, Duvillard L, Verges B, Olsson NO, Gambert P, Hillon P: Decreased plasma adiponectin concentrations are closely related to steatosis in hepatitis $C$ virusinfected patients. J Clin Endocrinol Metab 2005, 90(4):2240-2243.

16. Romeo S, Kozlitina J, Xing C, Pertsemlidis A, Cox D, Pennacchio LA, Boerwinkle E, Cohen JC, Hobbs HH: Genetic variation in PNPLA3 confers susceptibility to nonalcoholic fatty liver disease. Nat Genet 2008, 40:1461-1465

17. Valenti L, Al-Serri A, Daly AK, Galmozzi E, Rametta R, Dongiovanni P, Nobili V, Mozzi E, Roviaro G, Vanni E, et al: Homozygosity for the PNPLA3 / 
adiponutrin I148M polymorphism influences liver fibrosis in patients with nonalcoholic fatty liver disease. Hepatology 2010, 51:1209-1217.

18. Kotronen A, Johansson LE, Johansson LM, Roos C, Westerbacka J, Hamsten A, Bergholm R, Arkkila P, Arola J, Kiviluoto T, et al: A common variant in PNPLA3, which encodes adiponutrin, is associated with liver fat content in humans. Diabetologia 2009, 52(6):1056-1060.

19. Valenti L, Alisi A, Galmozzi E, Bartuli A, Del Menico B, Alterio A Dongiovanni P, Fargion S, Nobili V: I148M patatin-like phospholipase domain-containing 3 gene variant and severity of pediatric nonalcoholic fatty liver disease. Hepatology 2010, 52:1274-1280.

20. Trepo E, Pradat P, Potthoff A, Momozawa Y, Quertinmont E, Gustot T, Lemmers A, Berthillon P, Amininejad L, Chevalier M, et al: Impact of PNPLA3 (rs738409 C > G) polymorphism on fibrosis progression and steatosis in chronic hepatitis C. Hepatology 2011, 54:60-69.

21. Valenti L, Rumi M, Galmozzi E, Aghemo A, Del Menico B, De Nicola S, Dongiovanni P, Maggioni M, Fracanzani AL, Rametta R, et al: Patatin-Like phospholipase domain-containing 3 I148M polymorphism, steatosis, and liver damage in chronic hepatitis C. Hepatology 2011, 53(3):791-799.

22. Valenti L, Alisi A, Nobili V: I148M PNPLA3 variant and progressive liver disease: A new paradigm in hepatology. Hepatology 2012, 55(3): doi:10.1002/hep.25634

23. He S, McPhaul C, Li JZ, Garuti R, Kinch LN, Grishin NV, Cohen JC, Hobbs HH: A sequence variation (I148M) in PNPIA3 associated with nonalcoholic fatty liver disease disrupts triglyceride hydrolysis. J Biol Chem 2009, 285:6706-6715.

24. Qiao A, Liang J, Ke Y, Li C, Cui Y, Shen L, Zhang H, Cui A, Liu X, Liu C, et al: Mouse PNPLA3 influences systemic lipid and glucose homeostasis. Hepatology 2011, 54(2):509-521.

25. Chen W, Chang B, Li L, Chan L: Patatin-like phospholipase domaincontaining 3/adiponutrin deficiency in mice is not associated with fatty liver disease. Hepatology 2010, 52(3):1134-1142.

26. Santoro N, Kursawe R, D'Adamo E, Dykas DJ, Zhang CK, Bale AE, Cali AM, Narayan D, Shaw MM, Pierpont B, et al: A common variant in the patatinlike phospholipase 3 gene (PNPLA3) is associated with fatty liver disease in obese children and adolescents. Hepatology 2010, 52:1182-1189.

27. Ling H, Waterworth DM, Stirnadel HA, Pollin TI, Barter PJ, Kesaniemi YA, Mahley RW, McPherson R, Waeber G, Bersot TP, et al: Genome-wide linkage and association analyses to identify genes influencing adiponectin levels: the GEMS Study. Obesity (Silver Spring) 2009, 17(4):737-744

28. Richards JB, Waterworth D, O'Rahilly S, Hivert MF, Loos RJ, Perry JR, Tanaka T, Timpson NJ, Semple RK, Soranzo N, et al: A genome-wide association study reveals variants in ARL15 that influence adiponectin levels. PLOS Genet 2009, 5(12):e1000768.

29. Musso G, Gambino R, De Michieli F, Durazzo M, Pagano G, Cassader M: Adiponectin gene polymorphisms modulate acute adiponectin response to dietary fat: Possible pathogenetic role in NASH. Hepatology 2008, 47(4):1167-1177.

30. Bedogni G, Bellentani S, Miglioli L, Masutti F, Passalacqua M, Castiglione A, Tiribelli C: The Fatty Liver Index: a simple and accurate predictor of hepatic steatosis in the general population. BMC Gastroenterol 2006, 6:33.

31. Kleiner DE, Brunt EM, Van Natta M, Behling C, Contos MJ, Cummings OW, Ferrell LD, Liu YC, Torbenson MS, Unalp-Arida A, et al: Design and validation of a histological scoring system for nonalcoholic fatty liver disease. Hepatology 2005, 41(6):1313-1321.

32. Ishak K, Baptista A, Bianchi L, Callea F, De Groote J, Gudat F, Denk H, Desmet V, Korb G, MacSween RN, et al: Histological grading and staging of chronic hepatitis. J Hepatol 1995, 22(6):696-699.

33. Magni P, Ruscica M, Dozio E, Passafaro L, Steffani L, Morelli P, Banfi G, Corsi MM: Plasma adiponectin and leptin concentrations in professional rugby players. J Biol Regul Homeost Agents 2010, 24(1):87-91.

34. Gastaldelli A, Cusi K, Pettiti M, Hardies J, Miyazaki Y, Berria R, Buzzigoli E, Sironi AM, Cersosimo E, Ferrannini E, et al: Relationship between hepatic/ visceral fat and hepatic insulin resistance in nondiabetic and type 2 diabetic subjects. Gastroenterology 2007, 133(2):496-506.

35. Hui JM, Hodge A, Farrell GC, Kench JG, Kriketos A, George J: Beyond insulin resistance in NASH: TNF-alpha or adiponectin? Hepatology 2004 40(1):46-54

36. Sookoian S, Pirola CJ: Meta-analysis of the influence of I148M variant of patatin-like phospholipase domain containing 3 gene (PNPLA3) on the susceptibility and histological severity of nonalcoholic fatty liver disease. Hepatology 2011, 53(6):1883-1894.
37. Farrell GC: PNPLeAse get the fats right: does lipogenesis or lipolysis cause NASH? Hepatology 2010, 52(3):818-821.

38. Wang CW, Lin HY, Shin SJ, Yu ML, Lin ZY, Dai CY, Huang JF, Chen SC, Li SS, Chuang WL: The PNPLA3 I148M polymorphism is associated with insulin resistance and nonalcoholic fatty liver disease in a normoglycaemic population. Liver Int 2011, 31(9):1326-1331.

39. Palmer CN, Maglio C, Pirazzi C, Burza MA, Adiels M, Burch L, Donnelly LA, Colhoun H, Doney AS, Dillon JF, et al: Paradoxical Lower Serum Triglyceride Levels and Higher Type 2 Diabetes Mellitus Susceptibility in Obese Individuals with the PNPLA3 148 M Variant. PLoS One 2012, 7(6):e39362.

40. Hennige AM, Staiger H, Wicke C, Machicao F, Fritsche A, Haring HU, Stefan N: Fetuin-A induces cytokine expression and suppresses adiponectin production. PLOS One 2008, 3(3):e1765.

41. Pare G, Ridker PM, Rose L, Barbalic M, Dupuis J, Dehghan A, Bis JC, Benjamin EJ, Shiffman D, Parker AN, et al: Genome-wide association analysis of soluble ICAM-1 concentration reveals novel associations at the NFKBIK, PNPLA3, RELA, and SH2B3 loci. PLoS Genet 2011, 7(4): e1001374.

doi:10.1186/1471-230X-12-111

Cite this article as: Valenti et al:: The i148m Pnpla3 polymorphism influences serum adiponectin in patients with fatty liver and healthy controls. BMC Gastroenterology 2012 12:111

\section{Submit your next manuscript to BioMed Central and take full advantage of:}

- Convenient online submission

- Thorough peer review

- No space constraints or color figure charges

- Immediate publication on acceptance

- Inclusion in PubMed, CAS, Scopus and Google Scholar

- Research which is freely available for redistribution

Submit your manuscript at www.biomedcentral.com/submit
C Biomed Central 